\title{
Design Tools and Complexity: Mobile Games and Collective Imagination
}

\author{
Alexander Holland ${ }^{1}$, Stanislav Roudavski ${ }^{2}$ \\ ${ }^{1,2}$ University of Melbourne \\ ${ }^{2}$ https://unimelb.academia.edu/StanislavRoudavski \\ Ialexholland@me.com²stanislav.roudavski@cantab.net
}

This paper is based on a hypothesis that games can be used to support design decisions in a variety of complex situations. To explore this proposition, the research described below focuses on two aspects. Firstly, it experiments with the potential of games to be socially provocative. And secondly, it applies the induced provocations in support of collective imagination. This discussion is supported by a practical case study: a working prototype of a smartphone game that simulates urban cycling. The paper discusses utilisation of this game by diverse stakeholders in a workshop that sought to advance decision-making in a particularly vexatious stalemate.

Keywords: infrastructuring, virtual riding environments, collective imagination, provocating games, design negotiation, mobile games, urban cycling

\section{PROLOGUE: POCKETPEDAL}

Kelly cannot remember the last time she rode her bike. Maybe a couple of summers of ago, around the bay. Nor does she play videogames - the closest she gets is some Sudoku on her phone.

Most days Kelly drives. Even though she commutes past handsome trees and grand buildings, it is a stressful journey. Traffic is packed, and cyclists swerve in front of her without warning. Kelly heard they want to give more space to cyclists - as if finding a park is not already a struggle.

A friend mentions a related workshop, open to the public. Kelly is sceptical. She has filled feedback forms before. When she arrives a group of people is sitting down, eyes on the screens. "My best score ever!" someone laughs. Looking at their screens, she sees a world of blue cars and pink trees. "This is near my work," she says.
Kelly is given a phone. "GET TO THE CITY," the screen instructs. A cyclist appears, riding in the brightly coloured world - her city! Kelly taps the screen and the rider moves forward. She taps again and the avatar pedals faster. At the top left of the screen is a score, increasing steadily. Kelly thinks she can handle this. Some people lean over and start cheering her on.

A double-parked taxi slides into view, blocking her ride. Urgently, Kelly tap-tap-taps to avoid. A magenta car closes in from behind. "GET BACK TO THE BIKE LANE," her phone flashes. Kelly tries to return into the lane, but the car clips her.

"GAME OVER!" the phone states. "YOU GOT A SCORE OF 75, AND A BROKEN TOE!"

"Seventy-five?" someone notices. "Much better than my first time!" 


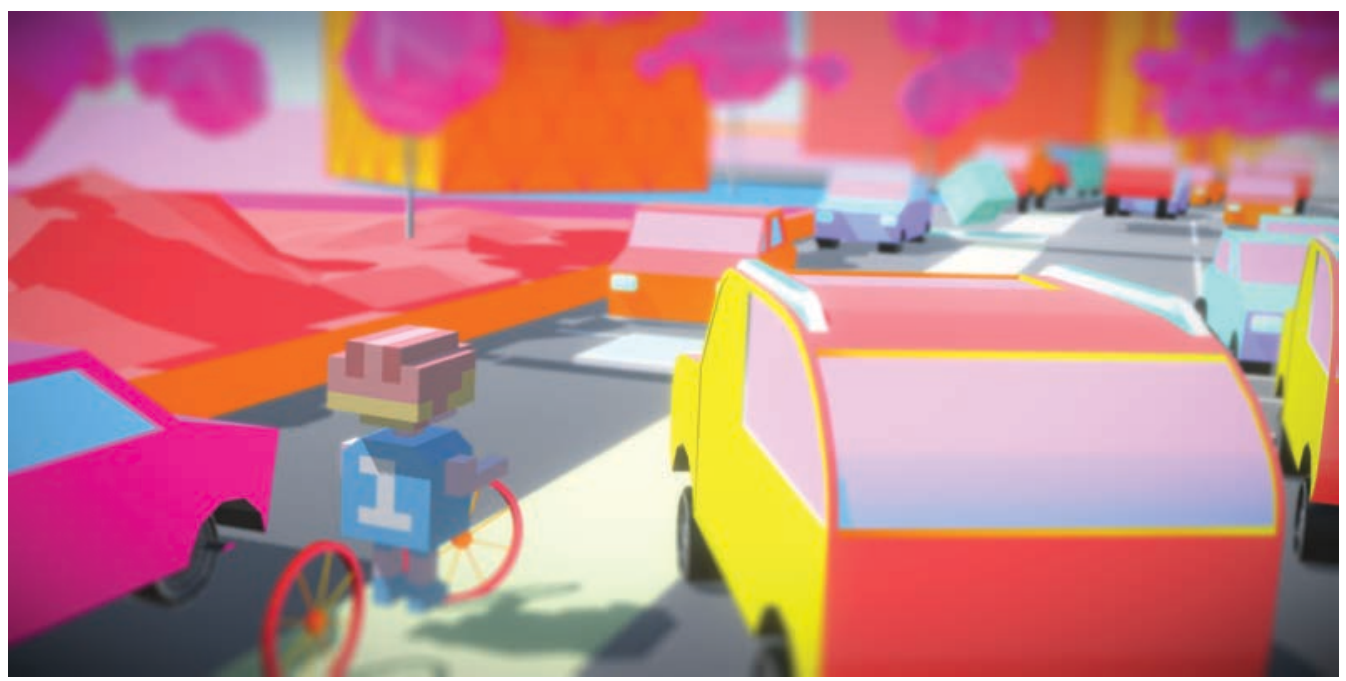

\section{INTRODUCTION: NEGOTIATING COM-} PLEXITY

The design value of experiences, such as those described above, can be significant for understanding constraints and opportunities. This paper argues that such experiences become even more powerful when they are shared with others. For example, the prologue's protagonist, Kelly, has an opportunity to experience a familiar environment via the circumstances typical to other stakeholders [Figure 1]. Through this lens, she acquires a deeper understanding of others' motivations and behaviours. Such experiences might prompt Kelly to rethink her preconceptions, encouraging her to look at riders in a new way. In provoking these deeper understandings, PocketPedal asks: are cyclists irresponsibly erratic? Is their behaviour avoidable? What can be done to support more equitable road conditions?

Increasingly, contemporary practice acknowledges that design problems are necessarily complex, dynamic and extended. This character of design challenges is particularly evident in urban settings. They are not only objectively complex, but are also highly contingent, dependent on stakeholders' value sys- tems and political persuasions. In situations where stakeholders disagree, progress to a particular solution may be difficult, or even impossible, unless the participants or potential beneficiaries can be persuaded to modify their attitudes, expectations and future actions. Understandably, this can be difficult; not only because of stakeholder reluctance, but also due to the difficulties people encounter in appreciating experiences of others and imagining feasible alternatives.

Urban cycling is utilised here as an illustrative case-study with which to meet this significant challenge. Recent research demonstrates that designers and planners need to broaden their knowledge of and often conflicting needs of urban travellers. Particularly relevant to urban cycling, it has been suggested that this recognition must be done before adequate design solutions can be realised that achieve greater participation in cycling (Bell \& Ferretti 2015).

Compatible with this need, design can be understood as a process of imagining together. This collective imagination is a public process even when insular, authoritarian design methods are engaged. specific modes of transport to recognise the diverse
Figure 1

PocketPedal, a mobile game of urban negotiation. The complex interactions between riders, urban infrastructure and traffic are recast in game format.

The characteristics of urban cycling are condensed with the aim to provoke and challenge. 
In more inclusive scenarios, designing overlaps with making of public cultures. Çınar and Bender (2007) discuss collective imagination as a totality of daily practices of urban dwellers. This paper seeks to emphasise how the particular attitudes and sophisticated personal knowledge (what can be termed selfexpertise) of individual stakeholders can be imported from the domain of the everyday into semi-formal design environments, where they can contribute to practical solutions. In such design settings, collective imagination emerges as a process of negotiation. Here, the role of professional designers and their design tools shifts from the production of final outcomes, to supporting the essential components of negotiation: promotion of empathy and trust, encouragement of conditions for safe experimentation, erosion of stereotypes and cultivation of common languages, amongst others.

Substantial and diverse work that engages with similar ideas already exists, loosely clustered around the notion of participatory design. Relevant themes include: a shift away from the designer as the controlling expert (Jones 1979); a move beyond 'infrastructure' as a noun to 'infrastructuring' as a verb (describing a collaborative design framework) (Karasti 2014; Clement et al. 2012); design for the inclusion of stakeholders beyond "users" (Szebeko \& Tan 2010; Binnekamp et al. 2006); explorations of emergent and interlinked ecologies (Thackara 2005; Fuller \& Matos 2011); and the structured search for unexpected potentials (Wood 2008). Seeking to extend this background through an innovative deployment of newly available digital tools, the research discussed in this paper explores opportunities provided by the introduction of games into such participatory design processes.

\section{PROVOCATIVE GAMES}

Traditional architectural representations are intended to communicate already-established ideas. Wishing to make the design process more inclusive and open, the PocketPedal project seeks to deploy media that reveals complex environmental inter- actions. In this context, games emerge as useful modes of engagement because they deploy generative mechanisms that can stage dynamic and immersive processes. To use a definition proposed by Salen \& Zimmerman (2004, p.80), "[a] game is a system in which players engage in an artificial conflict, defined by rules, that results in a quantifiable outcome." An influential school of thought promotes an argument that simulations are the core and unique characteristic of games (Frasca 2003). While the debate on whether this is the case continues, game strategies have been successfully expanding design methods in a variety of contexts (Mayer et al. 2005; Kuboya \& Kimura 2005). When working through games, designers do not shape stakeholders' experiences directly. They establish the rules of play; however, it is the direct experience of games as open-ended processes that encourages players to make meaningful inferences.

Consequently, interactive technologies such as games persuade in a variety of ways: through direct experience, consequential actions, engagement with other players and so on (Fogg 2003; Bogost 2007). When aiming to persuade, games can make critical arguments through the effects of gameplay events. In such cases, the mechanism of in-game interactions gains the capability to make political arguments and suggest collective action.

Indeed, there exists a substantial body of work on "serious" games, for example in education (Oak \& Bae 2014; Zielke et al. 2009; Walz \& Deterding 2014). Such games have been criticised for neglecting players' experience (Ferrara 2013) narrowing the gameplay options to the presentation of predetermined outcomes, similar to other types of media (Pelletier \& Kneebone 2015).

The position of this paper is that games can play serious roles in design processes without losing their identity as games. Deployed strategically, games have the potential to become useful design tools that can lead to new discoveries where designers and stakeholders create their own experiences in ways un-envisaged, or at least undirected, by the original 
game designers. Used in this context, games - and, specifically, the PocketPedal prototype -- share the conception and orientation of many strands of collaborative design. To evidence this point, the following section discusses how a synthesis of urban cycling and strategic game mechanics position PocketPedal not as a cycling simulator but as a provocative game that can be useful for participatory design.

\section{POCKETPEDAL}

PocketPedal is a game of real-time urban negotiation. Played on the phone, the game offers a safe, accessible alternative to experiencing cycling along a busy and dangerous inner-city road. In PocketPedal, players control a virtual cyclist and attempt to ride without crashing. By navigating the virtual route, players are exposed to the risks, challenges and high speed decision-making associated with urban riding.

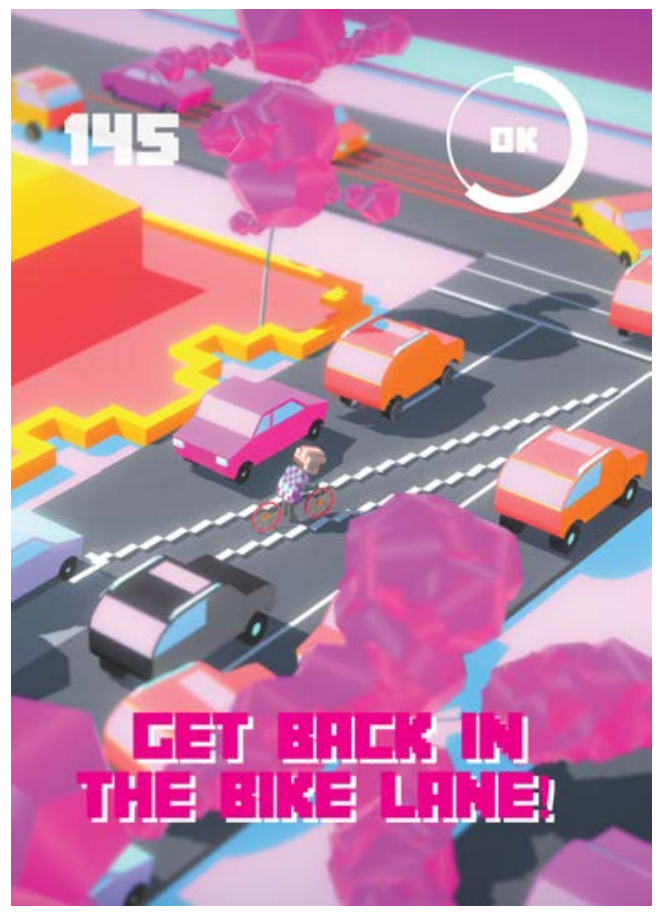

With an average penetration rate of $85 \%$ in the countries that are members of the Organisation for Economic Co-operation and Development (OECD), and over $100 \%$ in countries like Australia and the USA (OECD 2016), people are at ease with phones. The habitual use of touch devices means many of the potential stakeholders are already somewhat familiar with some aspects of the game's interaction model, regardless of prior gaming experience. Deployed on mobile devices, virtual worlds have the advantage of not needing specific spaces that can host gaming consoles, controllers or computer screens (Eriksson et al. 2005). They can instead be easily embedded into many types of activities and benefit from the richness of their surrounding contexts.

The virtual world of PocketPedal is a dangerous, intense but very popular two-kilometre bicycle journey through inner-city Melbourne. An analysis of cycling accidents revealed a segment of a major boulevard - St Kilda Road - where regular and serious events were particularly frequent (VicRoads 2016). PocketPedal implements road geometry, major intersections, car lanes and on-street parking spaces of the route. Combined with pavement markings related to bicycling and obstructions such as bollards and lane changes, these elements define a course that is demanding to navigate but rewarding to explore [Figure 2].

In contrast to previous virtual-cycling environments that often prioritise realism (Ranky et al. 2009; Välkkynen et al. 2001; Badland et al. 2010; Herpers et al. 2008; Kutz \& Herpers 2008), PocketPedal focuses on reconstructing complex and messy urban intensities. These infrastructural, logistical, cognitive, social and political effects are simplified, exaggerated and made accessible through play. Such safe accessibility - through the phone screen - is unconstrained by previous cycling experience of the participants and is accessible to a broad range of stakeholders.
Figure 2

A bike path crossing two lanes of traffic, representative of the poor cycling infrastructure, requires the player to negotiate multiple streams of fast traffic. 
Figure 3

A double parked taxi slides into view, blocking the path forward. As in real cycling, PocketPedal's unprotected bike lanes regularly force a player into the vehicular road-space. Ahead, a blue van opens its front door; a reminder that even on the bike path cyclists must always be vigilant.

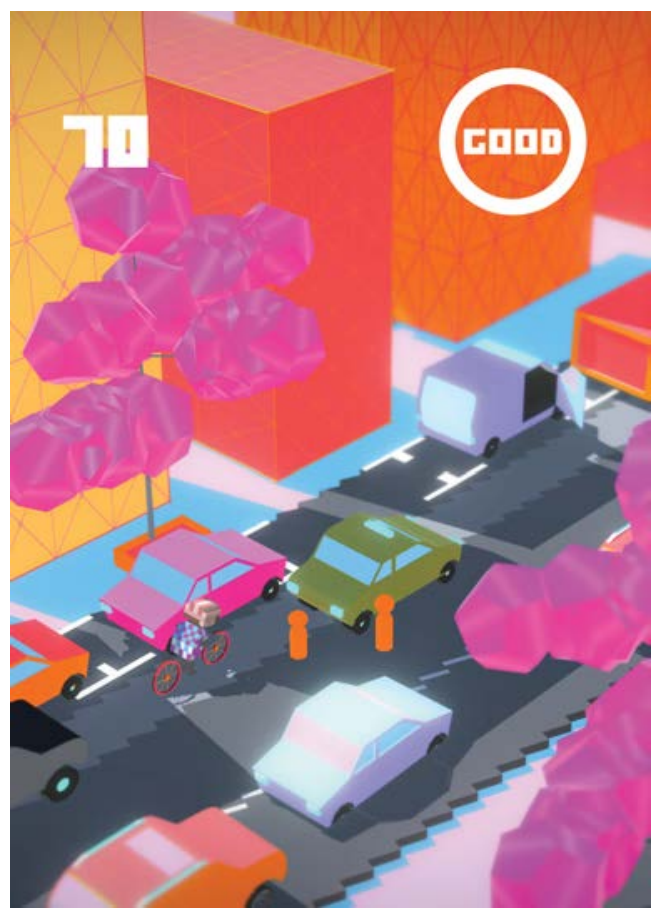

For instance, PocketPedal closely examines vulnerabilities of a cyclist in urban conditions. The game creates conditions where players operate in the state of constant alertness typical for cycling, where risks of bodily harm are much greater than that for motorists (Garrard et al. 2010). PocketPedal's procedurally generated and automatically operated vehicles modify road conditions in accordance with a weighting system developed from site observations. Such conditions change gradually, through multiple plays, but also suddenly - in close proximity to the virtual rider. Stationary vehicles become hazards by forcing players into traffic with their bulk or open doors [Figure 3]. Intruding into the experience of cycling, such situations closely resemble the dangers of parallel parking as demonstrated, for example by Johnson et al. (2013). An automated traffic system deploys individual vehicles with varying driving behaviours loosely based on recorded driver-cyclist interactions (Walker et al. 2014; Johnson et al. 2010). To give an example, a vehicle can be reckless: less likely to slow down near a player, and occasionally veering into the bicycle lane. By contrast, a vehicle could be moving in a way that matches the traffic flow and obeys road rules.

The typical game mechanics of scoring and health encourage players to examine the consequences of poor cycling infrastructure and unpredictable traffic. The game continuously assesses a player's behaviour via a metric of 'road health' that serves as a rough proxy for the fluctuating risk. This rating, prominently displayed on screen at all times, determines the amount of points the player is awarded at ten-metre increments. Road health decays when a player leaves the bicycle lane and increases when a player follows its path. Good road health is crucial for attaining a PocketPedal high score.

Through interaction with game mechanics such as these, PocketPedal imposes cognitive and emotional loads in players. On the road, a combination of infrastructural, behaviour and physical pressures contribute to the delegitimision of cyclists (Aldred 2012). Most intense in urban conditions, the need to resist this perceived message to 'get off the road!' is psychologically taxing. To provoke such a response in players, increasingly intense audio and visual warnings are deployed when the virtual cyclist leaves the bicycle lane and enters vehicular roadspace. This sensorial feedback, coupled with the threat of a collision and the consequential loss of health and points are an example of an approach that seeks to differentiate between the intensities of simulated urban environments. As cycling infrastructure frequently changes and can be blocked by doubleparked cars and open vehicle doors, players, just as real cyclists, have to rapidly evaluate and select actions in view of likely risks, while under time and scoring pressures [Figure 4]. Unlike on the actual road, these negotiations can be attempted in game multiples times, on multiple cycling runs, without any risk to life. 


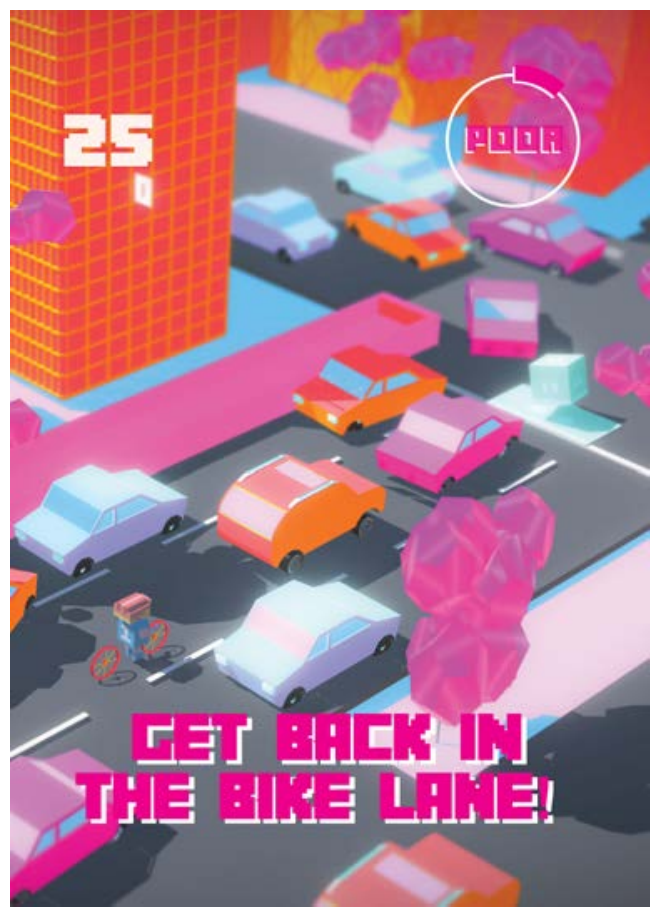

Extending the ideas clustered around the work on 'persuasive games', the research discussed in this paper also seeks to persuade, not directly, as propaganda is meant to do, but circuitously, by selfpersuasion, in a mode that is more akin to the arts. This approach deploys games as provocations that seek to pose questions and urge participants to find their own answers in the light of new experiences.

\section{COLLECTIVE IMAGINATION}

Based on the deployment of a fully functional prototype in the mixed-stakeholder PocketPedal workshop, this paper argues that games can contribute to design, especially when they are supported by other design tools and design processes. Such games are not intended as standalone products for individual play. Instead, they are used in the presence of various stakeholders including game developers as well as expert architects, urban planners and engineers.

Conventional gaming taxonomy would classify PocketPedal as a single player game, yet in a design context it is strategically collaborative. Beyond acting as means of enjoyment or education, PocketPedal seeks to provoke collective imagination. In one example, the pixelated, colourful, non-real rendering system urges participants to focus on events rather than on appearances, encouraging a debate about identities of urban settings. In another example, performance and road-health points awarded by the game become invitations for communication between players of different backgrounds and experiences.

The interface between play and players is vital for successfully embedding electronic games into wider participatory design activities. When a player 'loses' a game of PocketPedal by colliding with a vehicle, a physics engine calculates the force of impact and presents the player with a crash type and a typical injury. A slow side swipe might result in a broken toe; a high speed rear-end collision could lead to a broken neck. One the other hand, if a player navigates successfully, without crashing, a riding assessment is given according to a player's compliance with the cycling infrastructure. These crash and performance messages, informative and comically amplified, become mechanisms for transferring the player out of the virtual world and into an informed discussion with surrounding people.

In such settings, participatory strategies such as discussing, brainstorming, roleplaying or 'cardboard computing' (Pelle \& Kyng, 1991) can expand and enrich the interactions sustained within game environments. When games are embedded into a supportive setting, they do not need to be comprehensive, technically complete or conclusive. As in the case of PocketPedal, simulations that are embedded within them can aim to be accurate or deliberately misleading; the burden of meaning-making falling not to the games themselves, but to the participants who can play them alongside with other tactics.

To test the usefulness of games as tools for
Figure 4 Local unavailability of cycling infrastructure means a player is suddenly surrounded by moving vehicles. The player can choose to continue forward for extra points, or to turn left to the relative safety of the kerbside lane. Road health, seen in the top right corner, has dropped to 'poor', indicating the dangerous situation the player has found herself in. 
design negotiations, a fully functioning game prototype was built and deployed in the PocketPedal Workshop, a design workshop investigating the challenges of urban cycling along St Kilda Road. Workshop participants came from a diverse set of backgrounds, with different, potentially conflicting, understandings of the site. Stakeholders included cyclists, motorists, transit users, a planner from the local council and two health professionals. Data was collected through recorded conversations, and two questionnaires, one completed at the end of the workshop and the other a week later.

An extensive report on workshop activities and their impact on participants is beyond the scope of this text. Instead, this paper will briefly discuss two methods used to embed PocketPedal in participatory activities, and the rich interactions evoked from this collective imagining.

The first of these methods introduced stakeholders to PocketPedal, gradually giving individuals greater control. In this method, a volunteer plays PocketPedal on a large screen, riding according to the instructions given by other participants. Each of these playing partners is given control over a simple task associated with cycling: increasing or decreasing speed, opening or reacting to car doors and so on. Together, these participants form a collective cycling 'brain' that needs to interpret the conflicting commands of the group and navigate the game world.

Through this approach, specific aspects of cycling can be brought into focus. For example, the player's movement and speed can be controlled independently, by two different people. Others can modulate the actions, for example by adjusting the collective's attitude to risk. Feedback indicated that subdividing tasks in this way was useful:

- "I felt more confident analysing the game when we had one task assigned to us."

- "It made me realize there is a reason that cyclists sometimes have to ride in what may seem an "erratic" manner"

The analysis needed for such distributed cycling changes individual games into experiences of group negotiation. The decision of one participant has consequences for all. For example, if the participant controlling speed decides to go faster, the task of the person reacting to doors becomes more difficult. The effect is the collective moderation of behaviour. The group has a vested interest in 'winning' and collectively overrides less successful instructions, 'bleeding' commands across discrete tasks:

- [Speed Controller] "Go faster!"

- [Group] "No!!"

Thus, participants' actions are negotiated in the midst of experience and have immediate consequences: unsuccessful instructions leading to crashing. During the workshop, participants reported strong emotions, motivated by the immediate experience of the game.

- "When actually riding you have a protective bubble of hope - that the cars and trucks will avoid you. The game removes this comforting assumption and brings home the fact that the riders are so vulnerable."

- "By playing the game I have experienced viciously the feeling of cycling on St Kilda Road."

In contrast with shared play on a single screen as described above, the second method for provoking collective imagination involved individuals, each with their own phone unit, playing PocketPedal at the same time and in the same room. When participants can take complete control of the virtual cyclist they can adjust the experience for their needs. For example, players can rerun situations they want to experience again, with new tactics.

Compared to group play, individual play requires simultaneous personal management of multiple tasks: navigation, hazard detection, obstacle avoidance, risk assessment, prediction and so on. The flexibility of individual play makes it effective for exploring and testing cycling tactics in a safe environment. Yet PocketPedal played through this method is still experienced collectively. Players share scores, 
complain together about the game's inaccuracies, cheer each other on and commiserate with each other. Interactions like these create a safer space for collaboratively examining cycling. For example, cyclists and motorists could triangulate a potentially inflammatory discussion about road interaction on a shared language of high scores:

- A: "Two-twenty-eight. Two hundred and twenty-eight. Just saying."

- B: [Turns around in shock] "You got a score of 228??"

Follow-up interviews a week later indicated that playing PocketPedal in the workshop setting had a lasting effect on how some saw the route:

- "Especially for the motorists who have not ridden a bike since they were kids and see riders as bloody nuisances rather than legitimate road users. It changes their consciousness."

- "When I drive up, my focus is getting to the destination quickly without really taking in my surroundings. Playing the game has influenced the way I think in St Kilda Road now. I'm almost hyperaware of anything around me."

Through PocketPedal, a near-automatic daily commute becomes enriched with experiences of others. A cyclists' behaviours that might have been abstract, unpredictable and frustrating become understandable as consequences of decisions made by individuals who attempt to do the best when navigating a complex and difficult urban environment.

Methods that can help to disrupt habits and preconceptions can be productive in design many situations. Mundane experiences can obstruct complex processes from being understood, precluding productive negotiation and the invention of broadly suitable alternatives. Participant feedback indicates that imagining together through games can facilitate exchanges between diverse individuals with distinct worldviews and experiences. Negotiation between players, trial and error testing in a virtual environment, advice giving, friendly rivalry and score comparison create a reciprocal exchange of meaning. This engaging interaction can lead to individual and collective discoveries that would be impossible without such facilitation. Provocative games have the potential to reinforce such collaborative exchanges.

\section{CONCLUSION: LUDIC DESIGN TOOLKIT}

This paper describes PocketPedal, a smartphone game that generates constructive design provocations. The discussion of PocketPedal as an effective aid for collective imagination proposes that such games can be useful in design. This usefulness emerges from the deployment of games alongside other design tools, an assembly conceptualised here as a Ludic Design Toolkit. A detailed discussion of such toolkits cannot be accommodated within the confines of this paper. Furthermore, the application of such toolkits to large-scale practical problems is yet to be attempted and will have to be reported in subsequent publications.

Instead, this paper contributes by proposing experimentally motivated conceptualisations that can enrich and extend the spectrum of design methods. This spectrum already includes approaches that can be conceptualised as toolkits. For example, multiple, mature and widespread toolkits have significantly reduced time and expertise needed to create graphical user interfaces. Toolkits also exist in architectural and urban design (e.g., see Wart et al. 2010) where they can be known as methods, standards, regulations or survey and analysis techniques.

To expand this concept with additional options, the research described in this paper combines smartphone gaming with participatory-design techniques that include assessing video footage, playing cardbased games, enacting role-playing scenarios and encouraging discussions between diverse sets of stakeholders.

This work's interest in games is derived from their capabilities as simulations. Simulations are commonly understood as representations. As representations, they aim to establish a close relationship with 
some source environment, even in the cases where this relationship cannot be predictive, or even repeatable. By extending such ambitions and sometimes deliberately contradicting them, games can establish alternative goals. Rather than trying to accurately reproduce already-existing situations, they can stage various types of speculative systems that seek to interrogate the present or enact and critique possible futures. These systems can aim to explore imaginable interactions, stimulate learning and interrogation, provoke and even deliberately mislead to solicit engaged participation and meaningful response.

Noteworthy effects of direct participation made possible through the introduction of games and observed during this research project allowed: 1) inaction questioning of the typical and common simplifications of conventional urban roles such as drivers, pedestrians or cyclists; 2) exposure of implications of the perceived and practised habitual behaviours emanating from such stereotypical roles including commuting, parking or joyriding; 3) transpositions permitting one person to experience the world through the eyes of another: an elderly woman inhabiting a fast cyclist or a non-cyclist struggling to negotiate the traffic on a bike; 4) cultivation of sustained reflection about values, for example, expressed as binary tensions of game dynamics: convenience vs diversity, transit vs destination, commuting vs experiencing, convenience vs safety or selfassuredness vs collaboration.

In conclusion, the preliminary evidence suggests that the use of games can help to achieve and sustain productive participation. This use of provocative games in support of collective imagination does not replace the capabilities of already-establish tools but extends them in unusual and exciting ways.

\section{REFERENCES}

Aldred, R 2012, 'Incompetent or Too Competent? Negotiating Everyday Cycling Identities in a Motor Dominated Society', Mobilities, 8(2), pp. 252-271

Badland, HM, Opit, S, Witten, K, Kearns, RA and Mavoa, S 2010, 'Can Virtual Streetscape Audits Reliably Replace Physical Streetscape Audits?', Journal of Urban
Health, 87(6), pp. 1007-116

Bell, W and Ferretti, D 2015, 'What Should Planners Know about Cycling?', in Bonhom, J and Johnson, M (eds) 2015, Cycling Futures, University of Adelaide Press, Adelaide, AU, pp. 321-356

Binnekamp, R, van Gunsteren, LA, van Loon, PP and Barendse, P 2006, Open Design: A StakeholderOriented Approach in Architecture, Urban Planning, and Project Management, los Press, Amsterdam

Bogost, I 2007, Persuasive Games: The Expressive Power of Videogames, MIT Press, Cambridge, MA

Clement, A 2012 'Probing, Mocking and Prototyping: Participatory Approaches to Identity Infrastructuring', Proceedings of the 12th Participatory Design Conference: Research Papers - Volume 1, New York, pp. 21-30

Cınar, A and Bender, T 2007, 'The City: Experience, Imagination and Place', in Cınar, A and Bender, T (eds) 2007, Urban Imaginaries: Locating the Modern City, University of Minnesota Press, Minneapolis, MN, pp. xi-xxvi

Eriksson, D, Peitz, J and Bj।"ork, S 2005 'Socially Adaptable Games', Proceedings of the 2005 Digital Games Research Association (DIGRA) Conference: Changing Views: Worlds in Play, Vancouver, pp. 1-8

Ferrara, J 2013, 'Games for Persuasion: Argumentation, Procedurality, and the Lie of Gamification', Games and Culture, 8(4), pp. 289-304

Fogg, BJ 2003, Persuasive Technology: Using Computers to Change What We Think and Do, Morgan-Kaufmann, Amsterdam; Boston

Frasca, G 2003, 'Simulation versus Narrative: Introduction to Ludology', in Wolf, MJP and Perron, B (eds) 2003, The Video Game Theory Reader, Routledge, New York, pp. 221-235

Fuller, M and Matos, S 2011, 'Feral Computing: From Ubiquitous Calculation to Wild Interactions', The Fibreculture Journal(135), pp. 144-163

Garrard, J, Greaves, S and Ellison, A 2010, 'Cycling Injuries in Australia: Road Safety', Journal of the Australasian College of Road Safety, 21(3), pp. 37-43

Herpers, R, Heiden, W, Kutz, M, Scherfgen, D, Hartmann, U, Bongartz, J and Schulzyk, O 2008 'FIVIS Bicycle Simulator', Proceedings of the 2008 Conference on Future Play: Research, Play, Share, New York, pp. 244247

Johnson, M, Charlton, J, Oxley, J and Newstead, S 2010, 'Naturalistic Cycling Study: Identifying Risk Factors for On-Road Commuter Cyclists', Annals of Advances in Automotive Medicine, 54(Jan), pp. 275-283

Johnson, m, Newstead, S, Oxley, J and Charlton, J 2013, 
'Cyclists and Open Vehicle Doors: Crash Characteristics and Risk Factors', Safety Science, 59, pp. 135-140 Jones, JC 1979, 'Designing Designing', Design Studies, 1(1), pp. 31-35

Karasti, H 2014 'Infrastructuring in Participatory Design' Proceedings of the 13th Participatory Design Conference: Research Papers - Volume 1, New York, pp. 141150

Kuboya, M and Kimura, S 2005, 'The Game of "Forming a Coalition Government"', in Shiratori, R, Arai, K and Kato, $\mathrm{F}$ (eds) 2005, Gaming, Simulations and Society: Research Scope and Perspective, Springer, Tokyo, pp. $11-20$

Kutz, M and Herpers, R 2008 'Urban Traffic Simulation for Games', Proceedings of the 2008 Conference on Future Play: Research, Play, Share, New York, pp. 181-184

Mayer, I, Leijten, M, Carton, L, de Jong, M, Scalzo, R, Dammers, E and Verwest, F 2005, 'The Urban Network Game: A Simulation of the Future of Joint City Interests', in Shiratori, R, Arai, K and Kato, F (eds) 2005, Gaming, Simulations and Society: Research Scope and Perspective, Springer, Tokyo, pp. 39-48

Oak, JW and Bae, JH 2014, 'Development of Smart Multiplatform Game App Using Unity 3D Engine for CPR Education', International Journal of Multimedia and Ubiquitous Engineering, 9(7), pp. 263-268

Pelle, E and Kyng, M 1991, 'Cardboard Computers: Mocking-it-up or Hands-on the Future', in Greenbaum, J and Kyng, M (eds) 1991, Design at work Lawrence Erlbaum Associates, pp. 169-195

Pelletier, C and Kneebone, R 2015, 'Playful Simulations Rather than Serious Games: Medical Simulation as a Cultural Practice', Games and Culture, 11, pp. 1-25

Ranky, R, Sivak, M, Lewis, J, Gade, V, Deutsch, JE and Mavroidis, C 2009 'VRACK - Virtual Reality Augmented Cycling Kit: Design and Validation', 2010 IEEE Virtual Reality Conference, Waltham, MA, pp. 135-138

Salen, K and Zimmerman, E 2004, Rules of play: game design fundamentals, Cambridge, Mass. ; London : MIT Press, c2004.

Szebeko, D and Tan, L 2010, 'Co-designing for Society', Australasian Medical Journal, 3(9), pp. 580-590

Thackara, J 2005, In the Bubble: Designing in a Complex World, MIT Press, Cambridge, MA

Valkkynen, P, Heinila, J, Lainio, S, Lakaniemi, S and Vaatanen, A 2001 'Using Exercise Cycle as a Haptic Input Device in a Virtual Environment', Immersive Projection Technology and Virtual Environments 2001: Proceedings of the Eurographics Workshop, Stuttgart, pp.
229-235

Walker, I, Garrard, I and Jowitt, F 2014, 'The Influence of a Bicycle Commuter', Accident Analysis and Prevention, 64, pp. 69-77

Walz, SP and Deterding, S (eds) 2014, The Gameful World: Approaches, Issues, Applications, MIT Press, Cambridge, MA

Wood, J 2008 'Changing the Change: A Fractal Framework for Metadesign', Changing the Change: Design, Visions, Proposals and Tools, Turin, pp. 1-8

Zielke, Ma, Evans, MJ, Dufour, F, Christopher, TV, Donahue, JK, Johnson, $\mathrm{P}$, Jennings, EB, Friedman, BS, Ounekeo, PL and Flores, R 2009, 'Serious Games for Immersive Cultural Training: Creating a Living World', IEEE Computer Graphics and Applications, 29(2), pp. 49-60

[1] https://www.data.vic.gov.au/data/dataset/crashstats-data-extract

[2] http://www.oecd.org/internet/broadband-statisti cs-update.htm 


\section{University Library}

\section{- MINERVA \\ A gateway to Melbourne's research publications}

Minerva Access is the Institutional Repository of The University of Melbourne

Author/s:

Holland, A;ROUDAVSKI, S

Title:

Design Tools and Complexity: Mobile Games and Collective Imagination

Date:

2016-09-24

Citation:

Holland, A. \& ROUDAVSKI, S. (2016). Design Tools and Complexity: Mobile Games and Collective Imagination. Herneoja, A (Ed.) Österlund, T (Ed.) Markkanen, P (Ed.) The 34th International Conference on Research in Computer Aided Architectural Design in Europe (eCAADe): , 2, pp.555-564. eCAADe; University of Oulu. https://doi.org/10.52842/ conf.ecaade.2016.2.555.

Persistent Link:

http://hdl.handle.net/11343/115321 